\begin{tabular}{cc}
\hline International Journal of Aging Research \\
(ISSN:2637-3742)
\end{tabular}

\title{
Predictors of in-hospital mortality in critically ill Geriatric patients
}

\author{
Khalid E. Elsorady, MD
}

Department of Geriatrics and Gerontology, Faculty of Medicine, Ain Shams University, Cairo, Egypt

\section{ABSTRACT}

Objective: To determine the predictors of in-hospital mortality in critically ill older patients. Participants and Methods: A prospective cohort study including 305 critically ill older adults (age $\geq 60$ years) who were admitted to High Dependency Units (HDUs) in a tertiary care university hospital from March 22, 2019 to January 4, 2020. Demographic, clinical and laboratory data of participants were collected thought a review of medical records and clinical observation at HDUs till either death or discharge alive. Statistical analysis included univariate analysis of selected potential predictors such as various comorbidities, C- reactive protein / Albumin ratio (CAR), Neutrophil-lymphocyte ratio (NLR), Red cell distribution width (RDW), Po2/Fio2 ratio (PFR), Simplified acute physiology score II (SAPS II), Charlson comorbidity index (CCl) and multidrug-resistant Gram-negative bacterial (MDR-GNB) infection to ascertain their association with mortality, followed by multivariable logistic regression to derive the final prediction model. The discriminative ability of the model was evaluated by using the receiver operating characteristic (ROC) curve. RESULTS: Overall mortality was $53.1 \%$. Multivariate regression analysis revealed independent predictors of mortality including dementia in clinical history with an odds ratio (OR) of $4.86(95 \%$ $\mathrm{Cl}$ : 1.28-18.34), total protein with an OR of .53 (95\% Cl: .30-.95) and the use of mechanical ventilation (MV) and/or intravenous cardiovascular support with an OR of 148.34 (95\% Cl: 34.28-

${ }^{*}$ Correspondence to Author:

Khalid E. Elsorady, MD

Department of Geriatrics and Gerontology, Faculty of Medicine, Ain Shams University, Cairo, Egypt

Email: Khalid-elsorady@med.asu. edu.eg

How to cite this article:

Khalid E. Elsorady. Predictors of in-hospital mortality in critically ill Geriatric patients. International Journal of Aging Research, 2021, $4: 77$

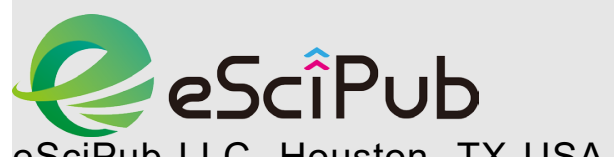
eSciPub LLC, Houston, TX USA. Website: https://escipub.com/ 641.77), formulating a novel prognostic model with an area under the ROC curve of .93 (95\% Cl: .89-.96, P.000). CONCLUSION: History of dementia, total protein and the use of MV and/or intravenous cardiovascular support are predictors of mortality in critically ill geriatric patients. It provides a novel prognostic model which needs validation in other multicenter prospective studies.

Keywords: Mortality, prognostic model, older adults, critical illness, dementia. 


\section{INTRODUCTION}

Look at the past to predict the future is a convenient concept for prognosis in critically ill older adults ${ }^{[1]}$. Traditional scoring systems lack accuracy in geriatric patients because of focusing on acute illness severity and lacking specific geriatric assessments ${ }^{[2]}$. As preexisting geriatric syndromes such as frailty, cognitive impairment and functional limitations are closely related to poor outcomes rather than age alone [3]. Cognitive impairment and comorbidity are common in critically ill older patients and could lead to the provision of less aggressive treatment or even treatment restriction, in addition to the increased risk of MDR-GNB infection and mortality ${ }^{[4-8]}$. MDR-GNB infection poses a clinical challenge because of resistance to nearly all antibiotics except colistin, some aminoglycosides, and variably tigecycline ${ }^{[9]}$ and it is associated with increased risk of mortality [10]. Also, there is increasing evidence that certain laboratory markers of inflammation such as RDW, C- reactive protein (CRP), NLR and CAR could also be associated with mortality in critically ill patients with various aetiologies ${ }^{[11-14]}$. Despite these concepts in prognosis, they are commonly neglected in various scoring systems. This study aims to identify predictors of inhospital mortality among critically ill geriatric patients through investigating the potential prognostic role of comorbidity, acute illness severity score, MDR-GNB infection and novel inflammatory markers including RDW, CRP, NLR and CAR.

\section{METHODOLOGY}

\section{Study Design, Setting and participants}

A prospective observational study including critically ill elderly patients who were admitted to HDUs including intermediate care unit and intensive care unit at Geriatrics hospital from March 22, 2019, to January 4, 2020. Geriatrics Hospital is a tertiary care hospital, designated for medical care of older adults (aged $\geq 60$ years). Exclusion criteria included patients with missing outcome or first admission data, and those who were transferred to another hospital or discharged against medical advice. Patients who were readmitted throughout the follow-up period till the end of January 2020 were included for one time, utilizing their first admission data.

\section{Demographic and clinical data collection}

Review of medical records was done for extraction of first admission clinical data including the main cause of admission, medical history of chronic diseases including dementia, initial vital signs and random blood glucose on admission to HDUs. Follow up was done through checking their clinical status for receiving renal replacement therapy and the use of MV and/or intravenous cardiovascular support (defined as the use of vasopressors and/or inotropes including Epinephrine, Norepinephrine, Dopamine and Dobutamine) during the period of stay at HDUs till either discharge alive or death. The primary outcome was mortality at HDUs.

\section{Laboratory Data collection}

Biological samples were collected by nursing staff members and assessed at the clinical laboratories of Ain Shams University hospital. Laboratory data collection was done through checking for laboratory results in medical records including arterial blood gases (ABG), CRP, total protein, albumin, aspartate transaminase, alanine transaminase, total bilirubin, blood urea nitrogen (BUN), creatinine, sodium, potassium, calcium, haemoglobin, hematocrit, white blood cell, RDW, and platelet. Diagnosis of MRD-GNB infection was confirmed by the available bacterial cultures and sensitivity either at admission or during the observation period. Different cultures and sensitivity to antibiotics were done by disc diffusion method. MDR was defined as acquired resistance to at least one agent in three or more antimicrobial categories ${ }^{[15]}$.

\section{Measurements and covariates of interest:}

Comorbidities assessment was based on the obtained medical history followed by $\mathrm{CCl}$ determination [16]. History of dementia was considered positive based on clinical symptoms 
obtained from patient's proxy coinciding with Diagnostic and Statistical Manual of Mental Disorders, Fourth Edition [17]. Calculation of acute illness severity score was done by SAPS II score ${ }^{[18]}$. Laboratory parameters on admission were used for calculation of inflammatory indicators. NLR is defined as the ratio of relative neutrophil to relative lymphocytes count ${ }^{[19]}$. The CAR was calculated by dividing the CRP level ( $\mathrm{mg} / \mathrm{L})$ by the serum albumin level $(\mathrm{g} / \mathrm{L})$ [20]. RDW was reported as part of a standard complete blood count to measure anisocytosis ${ }^{[12]}$. PFR was calculated by dividing Po2/Fio2 to assess initial oxygenation [21]. Estimation of $\mathrm{PaO} 2 / \mathrm{FiO} 2$ from oximeters is used for patients who had normal oxygen saturation on admission without available $\mathrm{PaO} 2$ in $\mathrm{ABG}$ parameters [22].

\section{Statistical analysis}

The analysis was performed by statistical package software IBM- SPSS version 21.
Values were presented as means \pm SD or as numbers and proportions, as appropriate. The relations between qualitative variables were evaluated by Chi-square test or Fisher's exact test, as indicated. Continuous variables were checked for normality by using Shapiro-Wilk test. As data were normally distributed, unpaired $\mathrm{t}$ test was used. Variables with $P$ values $<0.05$ in univariate analysis were introduced in a logistic regression model to detect independent predictors of mortality. Based on that prediction model was formulated as stated below. ROC curve was conducted to assess the sensitivity and specificity of the model in detecting mortality. All tests were bilateral and a $P$ value of $5 \%$ was the limit of statistical significance.

\section{Ethical consideration}

The study protocol was revised and approved by the Geriatrics hospital ethics review board and the ethical committee of the faculty of medicine at Ain Shams University.

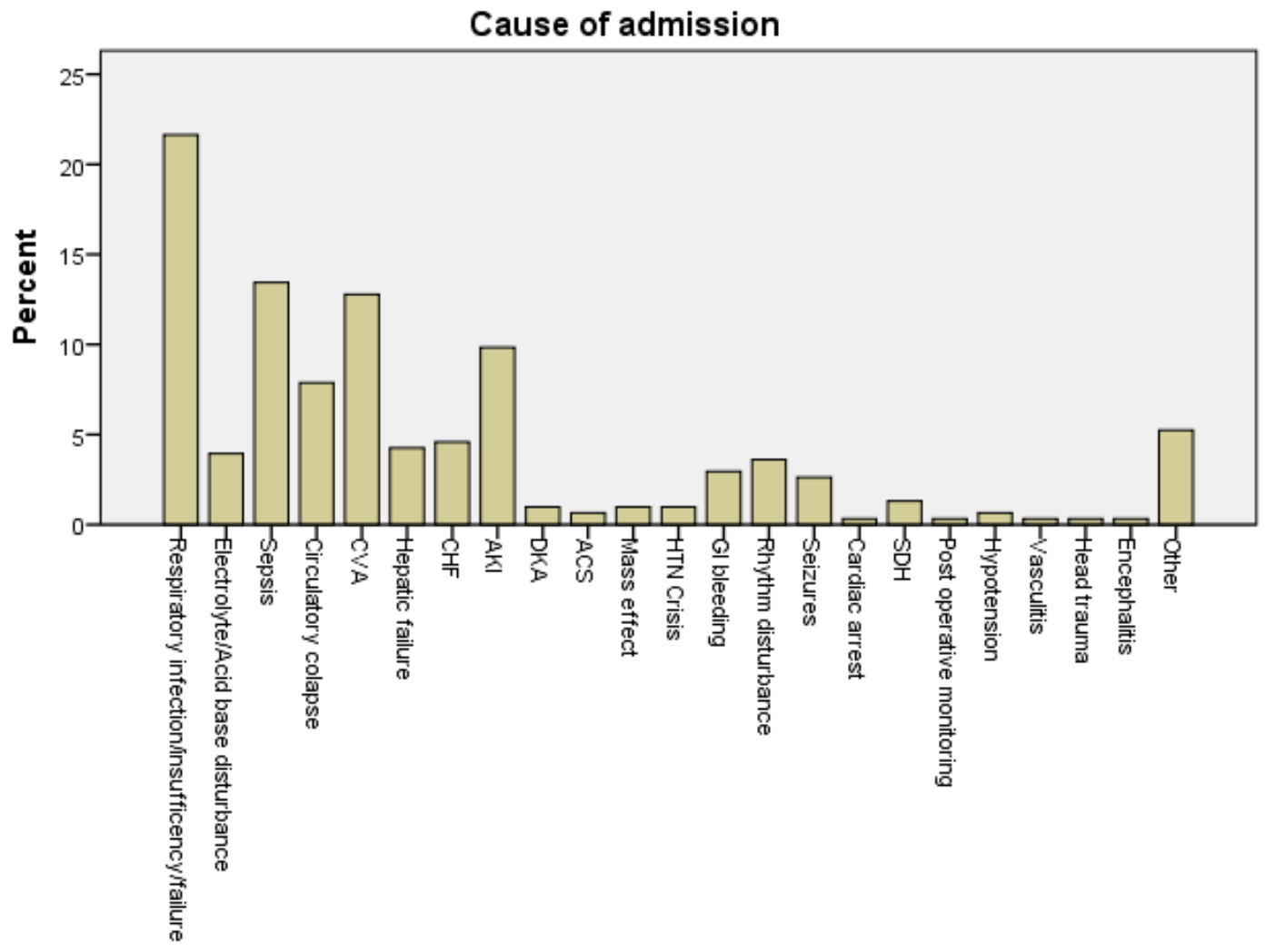

Cause of admission

Figure 1 Principal causes of admission in critically ill older adults

Abbreviations: Cerebrovascular accident (CVA), Congestive heart failure (CHF), Acute kidney Injury (AKI), Diabetic ketoacidosis (DKA), Acute coronary syndrome (ACS), Hypertensive crisis (HTN crisis), Gastrointestinal bleeding (Gl bleeding), Subdural hemorrhage (SDH). 


\section{RESULTS}

A total of 305 critically ill patients including 104 male (34.1\%) and 201 female (65.9\%) with an overall mortality rate of $53.1 \%$. Mean age of participants was $74.1 \pm 8.8$ years. The most common principal causes of admission were acute respiratory insufficiency/infection (ARI) $(21.6 \%)$, followed by sepsis $(13.4 \%)$, cerebrovascular accidents (12.8\%), acute kidney injury $(9.8 \%)$, circulatory collapse $(7.9 \%)$, congestive heart failure $(4.6 \%)$, hepatic failure $(4.3 \%)$ and electrolyte/acid-base disturbance (3.9\%) (Figure 1). Baseline characteristics and univariate analysis of quantitative and qualitative variables are described in Tables 1 and 2 respectively.

The variables significantly associated $(<0.05)$ with in-hospital mortality were history of dementia, history of malignancy, BUN, CAR, PFR, CCI, total protein, albumin, SAPS II score, sodium categories, the use of $\mathrm{MV}$ and/or intravenous cardiovascular support and the presence of MRD-GNB infection.

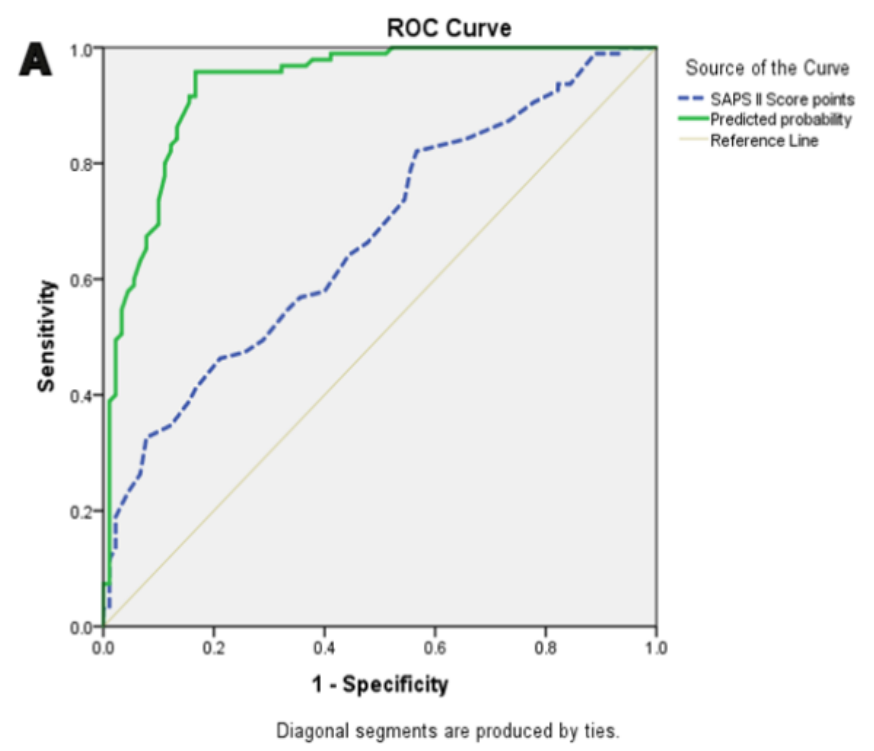

After multivariate analysis, history of dementia (OR= 4.86; $95 \% \mathrm{Cl}: 1.28-18.34 ; P=.020)$, total protein (OR=.53; 95\% Cl: .30- .95; $P=.035)$, and the use of $\mathrm{MV}$ and/or intravenous cardiovascular support (OR $=148.34 ; 95 \% \mathrm{Cl}$ : 34.28 641.77; $P=.000$ ) were predictors of in-hospital mortality and a novel predictive model has been formulated (table 3). This model can correctly predict $88.7 \%$ of mortality in the studied cohort and it was able to explain $71.5 \%$ of the variability of mortality (Nagelkerke $\mathrm{R}$ Square $=.715$ ) (Supplementary Dataset S1). Using a cut-off score .70 , this model predicted in-hospital mortality with a sensitivity $95.8 \%$ and a specificity $83.3 \%$. The area under the ROC curve (AUC) of this novel model was .93 $(95 \%$ Cl: .89-.96, $P=.000$ ), while AUC of SAPS II score was .67 (95\% Cl: .59-.74, $P=.000)$ (Figure 2A). A ROC curve was plotted also for inflammatory markers but none was significant for prediction of mortality at HDUs. The AUC of RDW, NLR and CAR was .57 (95\% Cl: .46-.69, $P=.174), .58$ $(95 \% \mathrm{Cl}: .47-.70, P=.125), \quad$ and .49 $(95 \% \mathrm{Cl}:$.38-.61, $P=.953)$, respectively (Figure 2B).

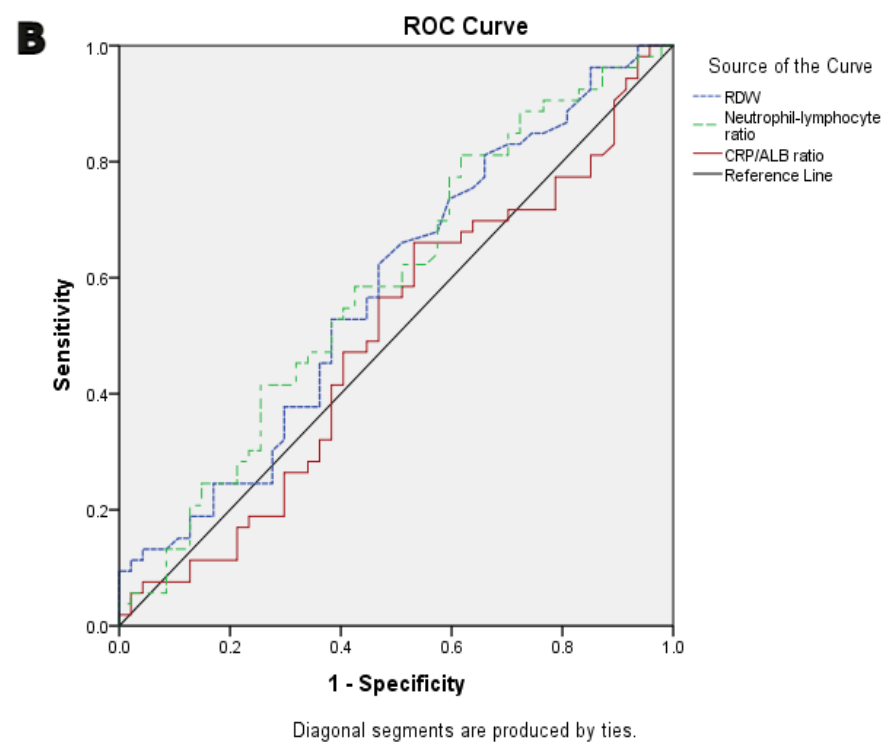

Figure 2 Receiver operating characteristic (ROC) curve of $(A)$ the novel prediction model and SAPS II Score (B) Inflammatory indicators: Red cell distribution width. Neutrophillymphocyte ratio and CRP/albumin ratio. (A) Area Under the Curve (AUC) of the novel prediction model is .93 (95\% Confidence Interval. .89-.96) while it is .67 (95\% Confidence Interval. .59-.74) for SAPS II Score; (B) AUC of inflammatory indicators: Red cell distribution width .57 (95\% Confidence Interval. .46-.69), Neutrophil-lymphocyte ratio .58 (95\% Confidence Interval. .47-.70), and CRP/ALB ratio. 49 (95\% Confidence Interval. .38-.61) 
Table 1 Baseline characteristics and univariate analysis for quantitative variables in critically ill older adults

\begin{tabular}{|c|c|c|c|c|}
\hline Quantitative Variables & $\begin{array}{r}\text { Mean } \pm S D \\
\text { (Number) }\end{array}$ & $\begin{array}{l}\text { Survivors } \\
46.9 \%(n=143)\end{array}$ & $\begin{array}{l}\text { Nonsurvivors } 53.1 \% \\
(\mathrm{n}=162)\end{array}$ & $P$ \\
\hline Age & $74.1 \pm 8.8(305)$ & $73.0 \pm 8.7(143)$ & $75.0 \pm 8.9(162)$ & .055 \\
\hline TLC & $12.1 \pm 8.8(305)$ & $11.3 \pm 7.2(143)$ & $12.9 \pm 10.0(162)$ & .116 \\
\hline NLR & $12.2 \pm 16.1(137)$ & $9.9 \pm 11.0(66)$ & $14.4 \pm 19.5(71)$ & .105 \\
\hline Hemoglobin & $10.5 \pm 2.2(304)$ & $10.5 \pm 2.1(143)$ & $10.4 \pm 2.4(161)$ & .680 \\
\hline Hematocrit & $32.0 \pm 8.8(264)$ & $32.0 \pm 7.3(125)$ & $31.9 \pm 9.9(139)$ & .926 \\
\hline Platelets & $236.5 \pm 113.2(304)$ & $236.6 \pm 112.6(143)$ & $236.3 \pm 114.0(161)$ & .978 \\
\hline BUN & $44.3 \pm 33.6(297)$ & $39.8 \pm 29.6(140)$ & $48.3 \pm 36.4(157)$ & .029 \\
\hline Creatinine & $1.8 \pm 1.7(303)$ & $1.8 \pm 1.4(142)$ & $1.8 \pm 1.9(161)$ & .999 \\
\hline RDW & $17.2 \pm 13.3(203)$ & $17.9 \pm 19.8(90)$ & $16.6 \pm 3.1(113)$ & .471 \\
\hline CRP & $100.3 \pm 92.1(275)$ & $90.8 \pm 96.2(130)$ & $108.8 \pm 87.7(145)$ & .107 \\
\hline Albumin & $2.7 \pm .6(282)$ & $2.8 \pm .6(132)$ & $2.6 \pm .6(150)$ & .001 \\
\hline CAR & $4.0 \pm 4.0(261)$ & $3.5 \pm 3.9(123)$ & $4.5 \pm 4.0(138)$ & .030 \\
\hline Sodium & $134.8 \pm 9.2(303)$ & $134.2 \pm 7.2(142)$ & $135.4 \pm 10.6(161)$ & .227 \\
\hline Potassium & $4.0 \pm .8(302)$ & $4.0 \pm .9(142)$ & $4.0 \pm .8(160)$ & .729 \\
\hline Corrected Calcium & $9.1 \pm 1.0(266)$ & $9.0 \pm .9(130)$ & $9.1 \pm 1.1(136)$ & .489 \\
\hline Phosphorus & $3.6 \pm 1.5(235)$ & $3.6 \pm 1.4(112)$ & $3.6 \pm 1.6(123)$ & .979 \\
\hline Magnesium & $1.9 \pm .4(255)$ & $1.9 \pm .4(121)$ & $1.9 \pm .5(134)$ & .986 \\
\hline Total protein & $5.9 \pm 1.0(224)$ & $6.2 \pm 1.1(107)$ & $5.7 \pm .8(117)$ & .000 \\
\hline Total bilirubin & $1.1 \pm 1.7(269)$ & $.9 \pm 1.1(127)$ & $1.3 \pm 2.1(142)$ & .063 \\
\hline ALT & $31.1 \pm 77.3(274)$ & $22.9 \pm 27.7(128)$ & $38.3 \pm 102.4(146)$ & .082 \\
\hline AST & $48.8 \pm 118.7(265)$ & $38.3 \pm 67.3(120)$ & $57.4 \pm 148.1(145)$ & .194 \\
\hline $\mathrm{PH}$ & $7.4 \pm .0(297)$ & $7.4 \pm .0(137)$ & $7.3 \pm .0(160)$ & .071 \\
\hline PFR & $341.3 \pm 130.6(285)$ & $361.2 \pm 113.4(132)$ & $324.1 \pm 141.9(153)$ & .016 \\
\hline RBS & $177.1 \pm 92.8(297)$ & $169.1 \pm 76.5(141)$ & $184.4 \pm 105.1(156)$ & .150 \\
\hline $\mathrm{CCl}$ & $7.8 \pm 2.5(293)$ & $7.4 \pm 2.3(136)$ & $8.2 \pm 2.5(157)$ & .010 \\
\hline SAPS II Score & $36.9 \pm 10.1(241)$ & $33.1 \pm 8.3(114)$ & $40.3 \pm 10.5(127)$ & .000 \\
\hline
\end{tabular}

Abbreviations: Total leukocyte count (TLC), Neutrophil-lymphocyte ratio (NLR), Blood Urea Nitrogen (BUN), Red cell distribution width (RDW), C-reactive protein (CRP), C-reactive protein/ Albumin ratio (CAR), Alanine aminotransferase (ALT), Aspartate transaminase (AST), Po2/Fio2 ratio (PFR), Random blood sugar (RBS), Charlson comorbidity index(CCI)., simplified acute physiology score II (SAPS II).

Normal range of TLC $\left(4-10 \times 10^{3} / \mu \mathrm{L}\right)$, Hemoglobin (12-15g/dl), Hematocrit (36-46\%), Platelets $\left(150-410 \times 10^{3} / \mu \mathrm{L}\right)$, BUN (5-23mg/dl), Creatinine (0.6-1.2mg/dl), RDW (11.5-14\%), CRP (<6mg/l), ALB (3.5-5.7g/dl), Sodium (136-145Mmol/l), Potassium (3.5-5.1Mmol/l), Total Calcium (8.6-10.3mg/dl), Phosphorus (2.5-5mg/dl), Magnesium (1.8-2.6mg/dl), Total protein (6-8.3g/dl), Total bilirubin (0.3-1 mg/dl), ALT (7-52IU/L), AST (3-35IU/L), RBS (80-140mg/dl). 
Table 2 Baseline characteristics and univariate analysis for qualitative variables in critically ill older adults

\begin{tabular}{|c|c|c|c|c|}
\hline Qualitative Variables & $\begin{array}{l}\text { Percentage } \\
\text { (Number) }\end{array}$ & $\begin{array}{l}\text { Survivors } \\
46.9 \%(n=143) \\
\end{array}$ & $\begin{array}{l}\text { Nonsurvivors } 53.1 \% \\
(n=162)\end{array}$ & $\mathrm{P}$ \\
\hline Men: women & $34.1(104): 65.9(201)$ & $47.1(49): 46.8(94)$ & $52.9(55): 53.2(107)$ & .954 \\
\hline \multicolumn{5}{|l|}{ Comorbidities } \\
\hline $\begin{array}{l}\text { CVD } \\
\text { (Yes) } \\
\text { (No) }\end{array}$ & $\begin{array}{l}76.7(234) \\
23.3(71)\end{array}$ & $\begin{array}{l}47.0(110) \\
46.5(33)\end{array}$ & $\begin{array}{l}53.0(124) \\
53.5(38)\end{array}$ & .938 \\
\hline $\begin{array}{l}\text { DM } \\
\text { (Yes) } \\
\text { (No) }\end{array}$ & $\begin{array}{l}46.9(143) \\
53.1(162)\end{array}$ & $\begin{array}{l}47.6(68) \\
46.3(75)\end{array}$ & $\begin{array}{l}52.4(75) \\
53.7(87)\end{array}$ & .826 \\
\hline $\begin{array}{l}\text { CVA/TIA } \\
\text { (Yes) } \\
\text { (No) }\end{array}$ & $\begin{array}{l}32.8(100) \\
67.2(205)\end{array}$ & $\begin{array}{l}46.0 \quad(46) \\
47.3(97)\end{array}$ & $\begin{array}{l}54.0 \quad(54) \\
52.7(108)\end{array}$ & .829 \\
\hline $\begin{array}{l}\text { CKD/ESRD } \\
\text { (Yes) }\end{array}$ & $24.3(74)$ & 52.7 (39) & $47.3(35)$ & .249 \\
\hline $\begin{array}{l}\text { (No) } \\
\text { Chronic hepatic disease } \\
\text { (Yes) }\end{array}$ & 75.7 (231) & $45.0(104)$ & $55.0(127)$ & .894 \\
\hline $\begin{array}{l}\text { (No) } \\
\text { History of malignancy } \\
\text { (Yes) } \\
\text { (No) } \\
\text { History of dementia } \\
\text { (Yes) }\end{array}$ & $\begin{array}{l}78.7(240) \\
15.1(46) \\
84.9(259) \\
33.1(101)\end{array}$ & $\begin{array}{l}47.1(113) \\
28.3(13) \\
50.2(130) \\
35.6(36)\end{array}$ & $\begin{array}{l}52.9(127) \\
71.7(33) \\
49.8(129) \\
64.4(65)\end{array}$ & .006 \\
\hline $\begin{array}{l}\text { (No) } \\
\text { Chronic respiratory } \\
\text { disease } \\
\text { (Yes) }\end{array}$ & $66.9(204)$ & $52.5(107)$ & $50.0(23)$ & .646 \\
\hline (No) & 84.9 (259) & $46.3(120)$ & 53.7 (139) & \\
\hline $\begin{array}{l}\text { MRD-GNB infection } \\
\text { (Yes) } \\
\text { (No) }\end{array}$ & $\begin{array}{l}42.6(130) \\
57.4(175)\end{array}$ & $\begin{array}{l}35.4(46) \\
55.4(97)\end{array}$ & $\begin{array}{l}64.6(84) \\
44.6(78)\end{array}$ & .001 \\
\hline $\begin{array}{l}\text { Use of MV and/or } \\
\text { intravenous } \\
\text { cardiovascular support } \\
\text { (Yes) } \\
\text { (No) }\end{array}$ & 41.5 (124) & 92.7 (115) & $\begin{array}{l}84.6(148) \\
7.3(9)\end{array}$ & .000 \\
\hline $\begin{array}{l}\text { Sodium Categories } \\
\text { Hyponatremia } \\
\text { Hypernatremia } \\
\text { Normal }\end{array}$ & $\begin{array}{l}50.8(153) \\
7.6(23) \\
41.5(125)\end{array}$ & $\begin{array}{l}49.0(75) \\
17.4(4) \\
48.8(61)\end{array}$ & $\begin{array}{l}51.0(78) \\
82.6(19) \\
51.2(64)\end{array}$ & .014 \\
\hline $\begin{array}{l}\text { High Creatinine } \\
\text { (Yes) } \\
\text { (No) }\end{array}$ & $\begin{array}{l}49.0(148) \\
51.0(154)\end{array}$ & $\begin{array}{l}48.6(72) \\
44.8(69)\end{array}$ & $\begin{array}{l}51.4(76) \\
55.2(85)\end{array}$ & .503 \\
\hline $\begin{array}{l}\text { Hemodialysis during stay } \\
\text { (Yes) } \\
\text { (No) }\end{array}$ & $\begin{array}{l}8.3(25) \\
91.7(276)\end{array}$ & $\begin{array}{l}40.0(10) \\
47.8(132)\end{array}$ & $\begin{array}{l}60.0(15) \\
52.2(144)\end{array}$ & .453 \\
\hline
\end{tabular}

Abbreviations: Cardiovascular disease (CVD), Diabetes mellitus (DM), Cerebrovascular accidents/Transient ischemic attacks (CVA/TIA), Chronic kidney disease/End Stage Renal disease (CKD/ESRD), Multidrug-resistant Gram-negative bacteria (MDR-GNB), Mechanical ventilation (MV). 


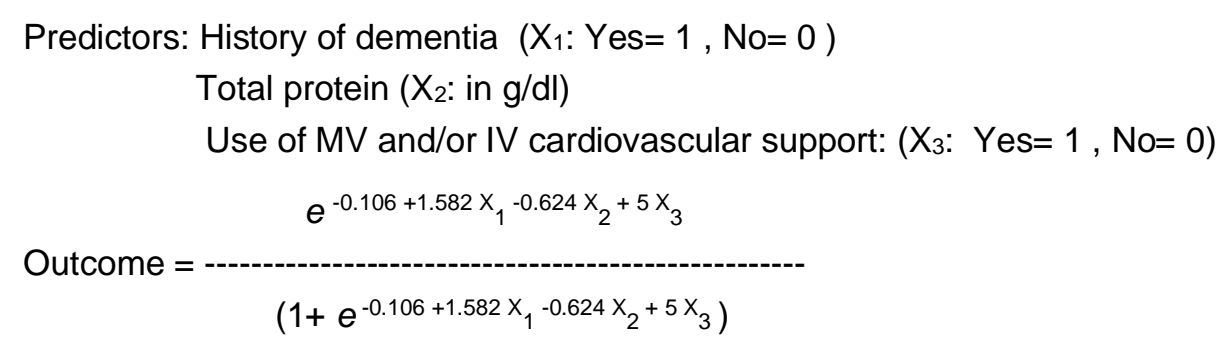

Outcome: $\quad$ Dead, if predicted probability $\geq 50 \%$

Alive, if predicted probability $<50 \%$

\section{DISCUSSION}

The study assessed the potential prognostic role of comorbidity, MRD-GNB infection and novel inflammatory indicators including CAR, RDW and NLR in critically ill older adults. History of dementia, total protein and the use of MV and/or intravenous cardiovascular support were independent predictors of in-hospital mortality and a novel predictive model has been developed. AUC of this model showed higher discriminative ability in comparison to SAPS II.

Both dementia and malignancy in the clinical history were significantly associated with mortality ( $P$ value .006). 101 patients (33.1\%) had a history of dementia and it predicted inhospital mortality. In comparison to other comorbidities, only history of dementia was associated with increased mortality hazard independent of other mortality risk factors and it is consistent with previous studies reporting this significant association between cognitive impairment and in-hospital mortality as in another prospective cohort study including hospitalized elderly patients [23], and a retrospective cohort study using databases of older people in England [24]. The importance of cognitive impairment in outcome prediction is also supported by large scale studies utilizing data from the Chinese Longitudinal Healthy Longevity Survey [25], and an integrative review of 104 articles reporting poorer hospital outcomes of older people with cognitive impairment [26]. This information confirms the value of cognitive screen at the time of admission of critically ill older patients.

Besides investigating the prognostic role of various comorbidities, this study investigated the impact of MRD-GNB infection on critically ill geriatric patients. MRD-GNB is the most dangerous group among MDR bacteria as infection with these bacteria is associated with significant morbidity and mortality worldwide [27]. This study showed that mortality in those who were infected with MRD-GNB was high, reaching $64.6 \%$ (84 patients), confirming the real challenge of this problem in the clinical settings and coinciding with data provided by The Global Point Prevalence Survey ${ }^{[28]}$. These findings are supported by other studies involving different age groups $[29,30]$.

Study results showed that non-survivors had statistically significant lower serum albumin than

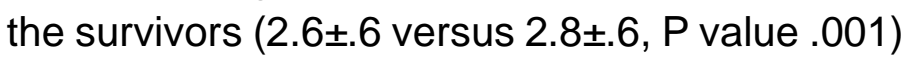
supporting the results of previous studies [31, 32]. These serum protein markers reflect an acute phase response and may not accurately represent the nutritional status in critical illness [33]. Also, non-survivors had a statistically significant lower serum total protein in comparison to survivors (5.7 \pm .8 versus $6.2 \pm 1.1$, $P$ value .000), a finding supported by another prospective study showing a relationship between total protein and mortality in hospitalized patients [34]. Despite these statistically significant associations between low serum albumin, low total protein and observed 
mortality, only low total protein has remained as an independent predictor in the regression model that elicits the search for the potential role of the albumin-globulin ratio as a novel prognosticator and a reflective of both malnutrition and inflammation as reported in a previous study including patients with chronic kidney disease ${ }^{[35]}$.

The third independent predictor of mortality in the study was the use of MV and/or intravenous cardiovascular support which is a well-known finding and supported by several previous studies [36, 37].

In this study comorbidity and acute illnesses severity assessments were conducted by $\mathrm{CCl}$ and SAPS II calculation, respectively and both were significantly associated with mortality at HDUs coinciding with other studies ${ }^{[29,36]}$.

The study did not show significant differences $(P$ value $<0.05$ ) concerning the use of hemodialysis during stay at HDUs, but non-survivors had statistically significant higher mean BUN $(48.3 \pm 36.4)$ coinciding with the results of other studies ${ }^{[34]}$. There were no significant differences $(P$ value $<0.05)$ concerning different serum electrolyte parameters on admission between the deceased patients at HDUs and those who were discharged alive, except for sodium categories on admission. The study showed that sodium categories had a significant association with death at HDUs ( $P$ value .014) coinciding with the reported importance of sodium level abnormalities on mortality among older adults [38, 39]. Additionally, non-survivors had a statistically significant lower PFR than the survivors (324.1 \pm 141.9 versus $361.2 \pm 113.4$ ), supporting the reported negative linear association between oxygenation and mortality [40].

The study also estimated the prognostic value of various inflammation-based markers. First, CAR represents a combination of markers for systemic inflammation and nutritional status ${ }^{[14]}$. Although it was significantly associated with mortality in the univariate analysis, it didn't remain as a predictor of mortality in the regression model and its AUC was .49 (95\%
Cl: .38-.61). Also, there was no significant association between CRP and in-hospital mortality. On the contrary, there are several studies demonstrating the prognostic value of CAR and CRP among hospitalized adults [14, 41, 42]. Second, the study didn't reveal a significant association between RDW, NLR and in-hospital mortality. ROC curves for RDW and NLR were used to assess their predictive ability and both had low AUC. It was .57 (95\% Cl: .46-.69) and $.58(95 \% \mathrm{Cl}: .47-.70)$ for RDW and NLR, respectively. This finding is inconsistent with other studies demonstrating their significant prognostic value ${ }^{[43,44]}$.

Despite the prognostic role of age among hospitalized elderly patients [23] and the associated risk of treatment restriction in older adults [37], this study showed that chronologic age is not a predictor of mortality and should not lead to treatment restriction. This finding is supported by other studies [7, 45, 46] as frailty, comorbidity and severity of illness are more important than age per se ${ }^{[47]}$. Also, gender was not found to be a predictor of mortality, supporting other findings of another prospective cohort study including hospitalized older adults [23, 46].

There were overlapping causes of admission at HDUs; this study demonstrated that ARI and sepsis are the 2 most common principal causes of admission among critically ill older adults, following previous reports ${ }^{[48,49]}$. The association between different principal causes of admission and mortality can't be assessed in this study as Chi-Square test was invalid for the analysis of this categorical variable also Fisher's Exact test wasn't applicable as the used SPSS statistical package in the study provides analytical results for $2 \times 2$ contingency tables only [50].

Strengths and Limitations: major strengths of this study include its prospective design and involvement of older adults only. This is the first study incorporating the search for the predictive role of comorbidity, novel inflammatory markers and MDR-GNB infection among older adults during critical illness to provide a simple 
prognostic model for this vulnerable group of patients. The key finding is the provision of an age-specific predictive model. The study has several limitations; first, it is a single institute study including a relatively small sample size especially for some variables such as NLR and without excluding patients with don't resuscitate orders. Second, diagnosis of dementia was merely based on clinical history and obtained by different clinicians from a proxy of each patient without objective cognitive assessment tools. Third, this novel prognostic model includes data that may not be attained on the first day of admission at HDUs that makes its application at the time of entry to HDUs limited in some degree, besides the combination of the use of MV with intravenous vasopressors / inotropes into one variable could lead to an inflation of its value in the model. Future studies should be conducted on a larger sample size and at more than one institutional centre as this study lacks a validation sample.

CONCLUSION: Dementia in clinical history, total protein and the use of MV and/or intravenous cardiovascular support are independent predictors of mortality in critically ill older adults that formulates a novel prognostic model. The model has strong discriminative abilities for mortality prediction. It could help clinicians dealing with geriatric patients, but it is not a self-fulfilling prophecy of death at the hospital and should not substitute clinical intuition and guidelines of management. It needs to be elucidated in other prospective multicenter studies with the investigation of additional variables for higher accuracy and better applicability.

\section{ACKNOWLEDGMENTS:}

The author acknowledges the technical assistance of Muhammad Elsorady, PhD, in data entry and management.

Author Contribution: The author is responsible for study design, data collection, analysis, interpretation, manuscript writing and revision.
Conflicts of interest: The author declares no conflicts of interest for this article

Funding: None

\section{REFERENCES}

[1]. Flaatten $\mathrm{H}$, Oeyen S, de Lange DW. Predicting outcomes in very old ICU patients: time to focus on the past? Intensive Care Med. 2018;44(8):1344-1345.

[2]. Guidet $\mathrm{B}$, Vallet $\mathrm{H}$, Boddaert $\mathrm{J}$ et al. Caring for the critically ill patients over 80: a narrative review. Ann Intensive Care. 2018;8:114.

[3]. Guidet B, de Lange DW, Boumendil A et al. The contribution of frailty, cognition, activity of daily life and comorbidities on outcome in acutely admitted patients over 80 years in European ICUs: the VIP2 study. Intensive Care Med. 2020;46(1):57-69.

[4]. Pittet D, Thievent B, Wenzel RP, Li N, Gurman $G$, Suter PM. Importance of pre-existing comorbidities for prognosis of septicemia in critically ill patients. Intensive Care Med. 1993;19(5):265-72.

[5]. Richardson SS, Sullivan G, Hill A et al. Use of aggressive medical treatments near the end of life: differences between patients with and without dementia. Health Serv Res. 2007;42(1 Pt 1):183-200.

[6]. Aliyu S, Smaldone A, Larson E. Prevalence of multidrug-resistant gram-negative bacteria among nursing home residents: A systematic review and meta-analysis. American Journal of Infection Control. 2017;45(5):512-8.

[7]. Skjaker SA, Hoel H, Dahl V, Stavem K. Factors associated with life-sustaining treatment restriction in a general intensive care unit. PLoS ONE. $\quad 2017 ; 12(7)$ : e0181312. Doi:10.1371/journal.pone.0181312

[8]. Hayat SA, Luben R, Dalzell $N$ et al. Understanding the relationship between cognition and death: a within cohort examination of cognitive measures and mortality. Eur $\mathrm{J}$ Epidemiol. 2018;33(11):1049-1062.

[9]. Falagas ME, Lourida P, Poulikakos P, Rafailidis PI, Tansarli JS. Antibiotic treatment of infections due to carbapenem-resistant Enterobacteriaceae: systematic evaluation of the available evidence. Antimicrob Agents Chemother. 2014;58(2):654-63.

[10]. Swaminathan M, Sharma S, Blash SP et al. Prevalence and risk factors for acquisition of carbapenem-resistant Enterobacteriaceae in 
the setting of endemicity. Infect Control Hosp Epidemiol. 2013;34(8):809-17.

[11]. Ho KM, Lee KY, Dobb GJ, Webb SAR. Creactive protein concentration as a predictor of in-hospital mortality after ICU discharge: A prospective cohort study. Intensive Care Med. 2008;34(3):481-487 .

[12]. Zhang $Z, X u X, N i ~ H$, Deng $H$. Red cell distribution width is associated with hospital mortality in unselected critically ill patients. J Thorac Dis. 2013;5(6):730-736.

[13]. Chen L, Lou Y, Chen Y, Yang J. Prognostic value of the neutrophil-to-lymphocyte ratio in patients with acute-on-chronic liver failure. Int $\mathrm{J}$ Clin Pract. 2014;68(8):1034-40.

[14]. Park JE, Chung KS, Song JH et al. The CReactive Protein/Albumin Ratio as a Predictor of Mortality in Critically III Patients. J. Clin. Med. 2018;7(10):333.

[15]. Magiorakos AP, Srinivasan A, Carey RB et al. Multidrug-resistant, extensively drug-resistant and pandrug-resistant bacteria: an international expert proposal for interim standard definitions for acquired resistance. Clin Microbiol Infect. 2012;18(3):268-81.

[16]. Charlson ME, Pompei P, Ales KL, MacKenzie CR. A new method of classifying prognostic comorbidity in longitudinal studies: development and validation. J Chronic Dis. 1987;40(5):373-83.

[17]. Widiger TA, Frances AJ, Pincus HA, First MB, Ross R, Davis W. American Psychiatric Association: Diagnostic and Statistical Manual of Mental Disorders, $4^{\text {th }}$ Edition. Washington, DC, American Psychiatric Association, 1994.

[18]. Le Gall JR, Lemeshow S, Saulnier F. A new Simplified Acute Physiology Score (SAPS II) based on a European/North American multicenter study. JAMA. 1993;270:2957-63.

[19]. Faria SS, Fernandes PC Jr, Silva MJ et al. The neutrophil-to-lymphocyte ratio: a narrative review. Ecancermedicalscience. 2016;10:702. Doi: 10.3332/ecancer.2016.702

[20]. Sun P, Chen C, Xia Y, Bi X, Liu P, Zhang F et al. The Ratio of C-Reactive Protein/Albumin is a Novel Inflammatory Predictor of Overall Survival in Cisplatin-Based Treated Patients with Metastatic Nasopharyngeal Carcinoma. Dis Markers. 2017;2017:6570808. Doi: 10.1155/2017/6570808.

[21]. ARDS. The ARDS Definition Task Force. Acute Respiratory Distress Syndrome: The Berlin Definition. JAMA.2012;307(23):2526-2533.
[22]. Sanz F, Dean N, Dickerson J et al. Accuracy of $\mathrm{PaO} 2 / \mathrm{FiO} 2$ calculated from $\mathrm{SpO} 2$ for severity assessment in ED patients with pneumonia. Respirology. 2015;20(5):813-818.

[23]. Almagro P, Ponce A, Komal $S$ et al. Multimorbidity gender patterns in hospitalized elderly patients. PLoS ONE. 2020;15(1): e0227252. Doi: 10.1371/journal. pone.0227252

[24]. Fogg C, Meredith P, Culliford D, Bridges J, Spice C, Griffiths P. Cognitive impairment is independently associated with mortality, extended hospital stays and early readmission of older people with emergency hospital admissions: A retrospective cohort study. Int $\mathrm{J}$ Nurs Stud. 2019; 96:1-8.

[25]. Duan J, Lv Y, Gao X et al. Association of cognitive impairment and elderly mortality: differences between two cohorts ascertained 6years apart in China. BMC Geriatrics. 2020; 20. 29. Doi: 10.1186/s12877-020-1424-4.

[26]. Fogg C, Griffiths P, Meredith P, Bridges J. Hospital outcomes of older people with cognitive impairment: An integrative review. Int J Geriatr Psychiatry. 2018;33(9):1177-1197.

[27]. Breijyeh Z, Jubeh B, Karaman R. Resistance of Gram-Negative Bacteria to Current Antibacterial Agents and Approaches to Resolve It. Molecules. 2020;25(6):1340.

[28]. Versporten A, Zarb P, Caniaux I et al. Antimicrobial consumption and resistance in adult hospital inpatients in 53 countries: results of an internet-based global point prevalence survey. The Lancet Global Health. 2018;6(6):e619-e629. Doi: 10.1016/S2214109X(18)30186-4.

[29]. Wang W, Jiang $T$, Zhang $W$ et al. Predictors of mortality in bloodstream infections caused by multidrug-resistant gram-negative bacteria: 4 years of collection. Am J Infect Control. 2017;45(1):59-64.

[30]. Siwakoti S, Subedi A, Sharma A, Baral R, Bhattarai NR, Khanal B. Incidence and outcomes of multidrug-resistant gramnegative bacteria infections in intensive care unit from Nepal- a prospective cohort study. Antimicrob Resist Infect Control. 2018;7:114.

[31]. Lyons O, Whelan B, Bennett K, O'Riordan $D$, Silke B. Serum albumin as an outcome predictor in hospital emergency medical admissions. Eur J Int Med. 2010;21(1):17-20.

[32]. Takegawa R, Kabata D, Shimizu K et al. Serum albumin as a risk factor for death in patients with 
prolonged sepsis: An observational study. J Crit Care. 2019;51:139-144.

[33]. Pierre S, Annika RB, Mette MB et al. ESPEN guideline on clinical nutrition in the intensive care unit. Clin. Nutr. 2018;1-32, Doi: 10.1016/j.clnu.2018.08.037.

[34]. Woo J, Mak YT, Lau J, Swaminathan R. Prediction of mortality in patients in acute medical wards using basic laboratory and anthropometric data. Postgrad Med J. 1992;68(806):954-960.

[35]. Wu PP, Hsieh YP, Kor CT, Chiu PF. Association between Albumin-Globulin Ratio and Mortality in Patients with Chronic Kidney Disease. J Clin Med. 2019;8(11):1991.

Doi:10.3390/jcm8111991

[36]. Suarez-de-la-Rica A, Castro-Arias C, Latorre J, Gilsanz F, Maseda E. Prognosis and predictors of mortality in critically ill elderly patients. Rev Esp Anestesiol Reanim. 2018;65(3):143-148.

[37]. Martin-Loeches I, Guia MC, Vallecoccia MS et al. Risk factors for mortality in elderly and very elderly critically ill patients with sepsis: a prospective, observational, multicenter cohort study. Ann Intensive Care. 2019;9(1):26.

[38]. Darmon M, Timsit JF, Francais A, Nguile-Makao $\mathrm{M}$, Adrie $\mathrm{C}$, Cohen $\mathrm{Y}$, et al. Association between hypernatraemia acquired in the ICU and mortality: a cohort study. Nephrol Dial Transplant. 2010;25(8):2510-5.

[39]. Holland-Bill L, Christiansen CF, HeideJørgensen $U$, Ulrichsen SP, Ring $T$, Jørgensen $\mathrm{JO}$, et al. Hyponatremia and mortality risk: a Danish cohort study of 279508 acutely hospitalized patients. Eur $\mathrm{J}$ Endocrinol. 2015;173(1):71-81.

[40]. Ramanan M, Fisher N. The Association between Arterial Oxygen Tension, Hemoglobin Concentration, and Mortality in Mechanically Ventilated Critically III Patients. Indian J Crit Care Med. 2018;22(7):477-484.

[41]. Oh, TK, Ji E, $\mathrm{Na} \mathrm{H}$ et al. C-Reactive Protein to Albumin Ratio Predicts 30-Day and 1-Year Mortality in Postoperative Patients after Admission to the Intensive Care Unit. Journal of Clinical Medicine. 2018;7(3): $39 . \quad$ Doi: 10.3390/jcm7030039.

[42]. Kompoti M, Drimis S, Papadaki A et al. Serum C-reactive protein at admission predicts inhospital mortality in medical patients. Eur $\mathrm{J}$ Intern Med. 2008;19(4):261-5.
[43]. Guo TM, Cheng B, Ke L, et al. Prognostic Value of Neutrophil to Lymphocyte Ratio for In-hospital Mortality in Elderly Patients with Acute Myocardial Infarction. Curr Med Sci. 2018;38(2):354-359.

[44]. Yousefi B, Sanaie S, Ghamari AA, Soleimanpour H, Karimian A, Mahmoodpoor A. Red Cell Distribution Width as a Novel Prognostic Marker in Multiple Clinical Studies. Indian J Crit Care Med. 2020;24(1):4954.

[45]. Le Borgne $P$, Maestraggi $Q$, Couraud $S$ et al. Critically ill elderly patients ( $\geq 90$ years): Clinical characteristics, outcome and financial implications. PLoS ONE. 2018;13(6):e0198360. https://doi.org/ 10.1371/journal.pone.0198360

[46]. Kır S, Bahçeci BK, Ayrancı E et al. Age is not a risk factor in survival of severely ill patients with co-morbidities in a medical intensive care unit. Ir J Med Sci. 2020; Doi: 10.1007/s11845-02002298-0

[47]. Muscedere J, Waters B, Varambally A et al. The impact of frailty on intensive care unit outcomes: a systematic review and meta-analysis. Intensive Care Med. 2017;43(8):1105-1122.

[48]. Sjoding MW, Prescott HC, Wunsch H, Iwashyna TJ, Cooke CR. Longitudinal changes in ICU admissions among elderly patients in the United States. Crit Care Med. 2016; 44(7):1353-60.

[49]. Laporte L, Hermetet C, Jouan Y, Gaborit C, Rouve E, Shea K et al. (2018). Ten-year trends in intensive care admissions for respiratory infections in the elderly. Ann. Intensive Care. 2018; 8:84.

[50]. Kim HY. Statistical notes for clinical researchers: Chi-squared test and Fisher's exact test. Restor Dent Endod. 2017;42(2):152-155. 